\title{
Impact of diet on adult hippocampal neurogenesis
}

\author{
Doris Stangl $\cdot$ Sandrine Thuret
}

Received: 17 July 2009/Accepted: 20 July 2009/Published online: 15 August 2009

(C) Springer-Verlag 2009

\begin{abstract}
Research over the last 5 years has firmly established that learning and memory abilities, as well as mood, can be influenced by diet, although the mechanisms by which diet modulates mental health are not well understood. One of the brain structures associated with learning and memory, as well as mood, is the hippocampus. Interestingly, the hippocampus is one of the two structures in the adult brain where the formation of newborn neurons, or neurogenesis, persists. The level of neurogenesis in the adult hippocampus has been linked directly to cognition and mood. Therefore, modulation of adult hippocampal neurogenesis (AHN) by diet emerges as a possible mechanism by which nutrition impacts on mental health. In this study, we give an overview of the mechanisms and functional implications of AHN and summarize recent findings regarding the modulation of AHN by diet.
\end{abstract}

Keywords Adult hippocampal neurogenesis .

Neural stem cells $\cdot$ Diet $\cdot$ Nutrition .

Learning and memory $\cdot$ Mood

\section{Introduction}

As much as diet has an impact on cardiovascular health, cancer risks and longevity, it has also an impact on mental health. Research over the last 5 years has now clearly established that our learning and memory abilities, as well

D. Stangl $\cdot$ S. Thuret $(\bowtie)$

Centre for the Cellular Basis of Behaviour and MRC Centre for Neurodegeneration Research, The James Black Centre, Institute of Psychiatry, King's College London, 125 Coldharbour Lane, London SE5 9NU, UK e-mail: sandrine.1.thuret@kcl.ac.uk as our mood, can be influenced by diet, not only during development, but also during adulthood (reviewed in [35]). For example, low intake of omega-3 fatty acids is associated with several forms of cognitive decline in the elderly [31], whereas a diet rich in it is associated with the prevention of cognitive decline [116]. Interestingly, rodents with omega-3 fatty acids deficiency showed impaired performance in spatial memory tasks, which could be rectified after dietary replenishment [26]. Moreover, omega-3 fatty acid concentrations are lower in patients with depression [68], and its supplementation has even emerged as a potential treatment for depression [30, 42]. Likewise, the intake of flavonoids is positively correlated with cognitive function [119] and mood [78]. Although these studies emphasize an important role of diet on mental health, further work is necessary to determine the mechanisms underlying these behavioural effects.

One of the brain structures associated with learning and memory, as well as mood, is the hippocampus. Interestingly, the hippocampus is one of the two structures in the adult brain where the formation of newborn neurons, or neurogenesis, persists. Adult hippocampal neurogenesis (AHN) has been linked directly to cognition and mood (reviewed in [126]); therefore, modulation of AHN by diet could emerge as a possible mechanism by which nutrition impacts on mental health. In this study, we give an overview of the mechanisms and functional implications of AHN and summarize recent findings regarding its modulation by diet.

\section{Neural progenitor/stem cells, adult hippocampal neurogenesis and the neurogenic niche}

Neural progenitor cells are self-renewing, multipotent cells that generate neurons, astrocytes and oligodendrocytes in 
the nervous system [32]. Although neural progenitor cells with the potential to give rise to neurons in vitro appear to be ubiquitously present within the adult mammalian CNS, newborn neurons have been consistently found only in two privileged areas of the adult brain: the subgranular zone (SGZ) in the dentate gyrus of the hippocampus [48] and the subventricular zone (SVZ) of the lateral ventricles [2] (Fig. 1). Adult neurogenesis has been found in all mammals studied to date, including humans [24]. The process of adult neurogenesis encompasses the proliferation of resident neural progenitor cells and their subsequent differentiation, migration and functional integration into the pre-existing circuitry. During AHN (Fig. 1), neural progenitor cells proliferate in the SGZ and give rise to immature neurons. Many die within 2 weeks, but the surviving neurons then migrate into the molecular layer [51]. The surviving neurons then send axons to the CA3 region and the hilus to form functional synapses with hilar interneurons and CA3 neurons within 3 weeks [113]. Next, these new neurons start also to receive synaptic inputs from the cortex and are capable of firing action potentials [118]. Therefore, these newly generated neurons become physiologically mature and functionally integrated in the circuit.

It is still not perfectly understood why neurogenesis is restricted to the hippocampus and the SVZ, given that neural progenitor cells have been isolated from many CNS regions. It is hypothesized that the microenvironments of the SGZ and SVZ, known as the neurogenic niche, may have specific factors that are permissive for the differentiation and integration of new neurons [81]. In the SGZ, adult hippocampal progenitors are found within a dense layer of granule cells. Within this microenvironment, there are also astrocytes, oligodendrocytes, other types of neurons and blood vessels. Anatomical analysis has identified the vasculature as one potential important constituent of the neurogenic niche [90]. Hippocampal astrocytes also play an important role in AHN as they have been shown to promote the neuronal differentiation of adult hippocampal progenitor cells and the integration of newborn neurons [102]. Blockade of the Wnt signalling pathway inhibits the neurogenic activity of astrocytes in vitro and AHN in vivo, suggesting that hippocampal astrocytes may act through this pathway [66]. Another study also suggests that astrocytes in areas outside the SGZ and SVZ of adult mice express high levels of ephrinA2 and -A3, which present an inhibitory niche, negatively regulating neural progenitor cell growth [45].

\section{Molecular and epigenetic control of adult hippocampal neurogenesis}

The control of AHN is very complex and remains to be fully elucidated. Over the last 10 years, many signals have been implicated in the regulation of AHN and they intervene at the stages of proliferation, differentiation, migration and integration. In the following, we highlight some of the important molecular players in the regulation of AHN known to date.

Regulation of proliferation and differentiation of adult hippocampal progenitor cells

\section{Extrinsic factors}

Morphogens, growth factors, cytokines, neurotransmitters and hormones are extrinsic factors that have been found to play a role in regulating AHN (reviewed in [126]). We highlight here some of the important and potentially relevant factors relating to nutrition. Over ten growth factors and neurotrophins have been found to influence AHN. Fibroblast growth factor (FGF-2) and epidermal growth factor (EGF) are the primary mitogens used in vitro to propagate neural progenitor cells, and FGF-2 is hypothesized to play a permissive role in vivo in hippocampal progenitor cell proliferation [82]. Indeed, it has been found that deletion of fibroblast growth factor receptor- 1 in the CNS decreases hippocampal progenitor cell proliferation [127]. Another key growth factor is brain-derived neurotrophic factor (BDNF), which has been shown to increase AHN when infused into the hippocampus [99]. BDNF binds several receptors, including p75 and TrkB, and decrease in either TrkB activity or BDNF protein levels causes reductions in neurogenesis [65, 97]. However, controversy still exists on how BDNF affects neurogenesis (e.g. proliferation vs. survival/differentiation). Hormones have also been shown to modulate $\mathrm{AHN}$; for example, corticosterone decreases proliferation and neurogenesis [11] and male pheromones increase neurogenesis in female mice [71]. The target cells of many extrinsic factors are unknown; therefore, in addition to direct potential effect on the progenitor cells, these growth factors could promote changes in other cell types within the neurogenic niche and have an indirect influence on adult hippocampal progenitors.

\section{Intracellular factors}

We highlight here some recently identified intracellular mechanisms implicated in AHN, including some transcription factors and epigenetic modulators. Several transcription factors have been shown to play critical roles in AHN. Amongst these, TLX, an orphan nuclear receptor, is required for proliferation $[17,125]$ and the basic helixloop-helix transcription factors, Neurogenin2 (Ngn2) and NeuroD, direct proliferation and specify neuronal fate, respectively [96]. In addition, genes involved in cell cycle 
Fig. 1 Schematic representation of the sagittal view of a rodent brain highlighting the two neurogenic zones of the adult mammalian brain: the subventricular zone $(S V Z)$ of the lateral ventricles and the subgranular zone of the dentate gyrus $(D G)$ in the hippocampus. Neurons generated in the SVZ migrate through the rostral migratory stream $(R M S)$ and are incorporated into the olfactory bulb. The hippocampal region contained in the black square is enlarged showing (1) neural progenitor cells in the SGZ of the DG proliferating, (2) migrating into the granule cell layer and (3) maturing into new granule neurons. These integrate into the hippocampal circuitry by receiving inputs from the entorhinal cortex and extend projections into the CA3

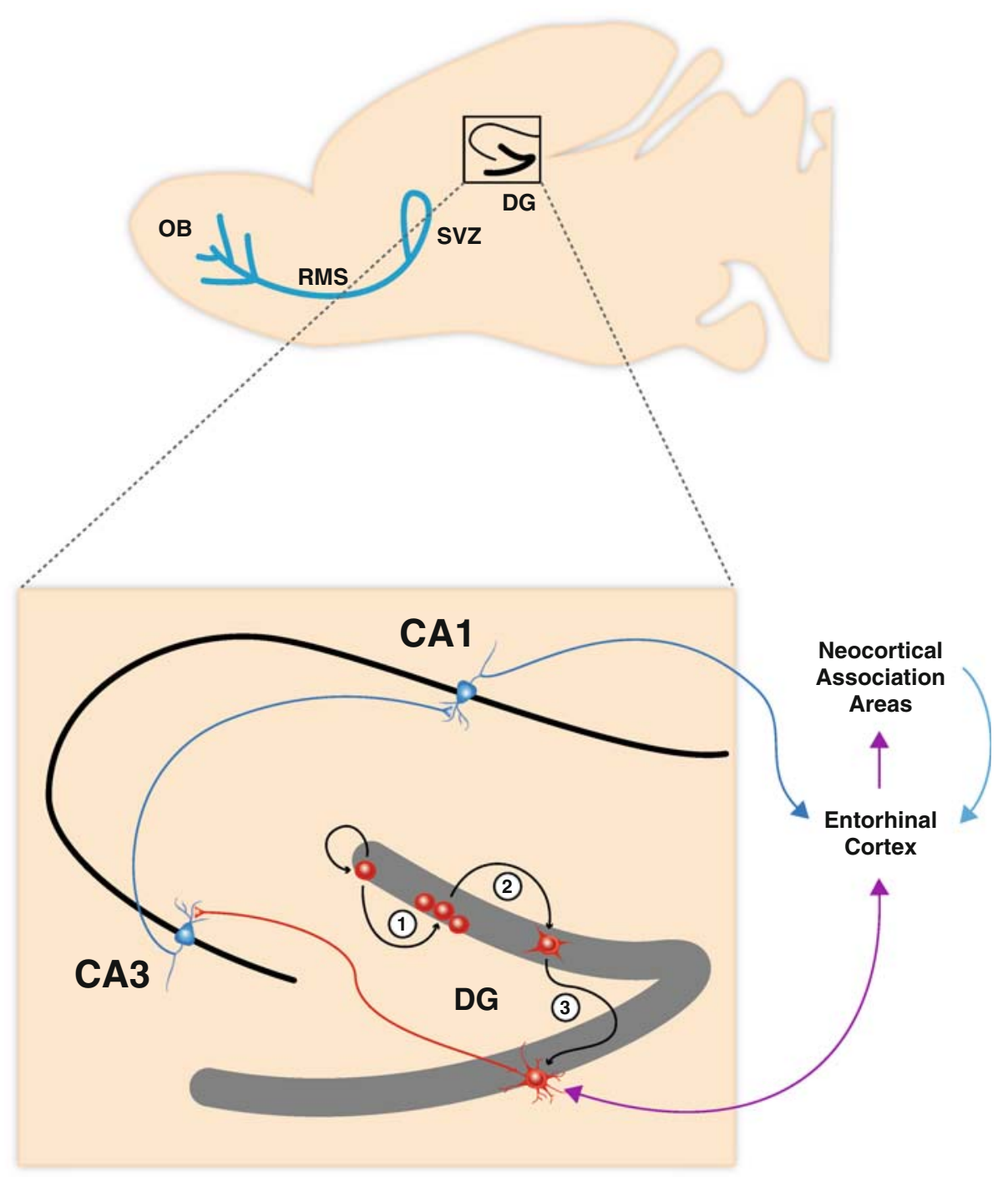

regulation, DNA repair and chromosomal stability are required for the proper function of the adult hippocampal progenitor (reviewed in [126]). Moreover, AHN is also subject to epigenetic regulation, and both DNA methylation and histone acetylation are important. For example, the histone deacetylase inhibitor, valproic acid, induces neuronal differentiation of adult hippocampal progenitors most likely through the induction of neurogenic transcription factors including NeuroD [39]. Furthermore, mice with Gadd45b deletion exhibit specific deficits in neural activity-induced proliferation. Mechanistically, Gadd45b is required for activity-induced DNA demethylation of BDNF and FGF promoters [70].

\section{Migration}

Newborn neurons in the adult hippocampus only migrate a short distance into the granule cell layer and little is know about the regulation of this step. It has been suggested that cyclin-dependent kinase 5 (cdk5) is involved in migration, as single cell-specific knockdown of cdk5 in newborn hippocampal cells leads to aberrant growth of dendritic processes, which is associated with an altered migration pattern of newborn cells [43]. Disrupted-in-Schizophrenia (DISC1) has also been implicated as its down-regulation leads to aberrant migration further into the granule cell layer [20]. A more recent study shows that DISC1 is also involved in proliferation of adult hippocampal progenitor cells through the GSK $3 \beta / \beta$-catenin signalling pathway [73].

Survival and integration

As described earlier, newborn neurons integrate into the hippocampal circuitry; however, the mechanisms involved in their integration are currently not well understood. Nevertheless, studies have shown that the survival of newborn neurons depends on sensory inputs. For example, 
their survival is influenced by the animal's experience, such as exposure to an enriched environment. Signalling through the glutamate $N$-methyl-D-aspartate (NMDA) receptor plays a cell autonomous role in the neuron surviving during the third week after birth and coincides with the formation of dendritic spines and glutamatergic inputs [109].

\section{Functionality of adult hippocampal neurogenesis}

The data discussed above clearly demonstrate that adultborn hippocampal neurons are functional and integrate into the hippocampal circuitry. However, the incorporation of AHN into current concepts of hippocampal network function and behaviour is complex.

\section{Learning and memory}

The implication of AHN in learning and memory is supported by some correlative and ablation studies, as well as by computational modelling. AHN varies amongst different genetic backgrounds in mice and a correlation between the level of hippocampal neurogenesis and the performance in hippocampal-dependent learning tasks is observed between mice of different strains [49, 112]. Environment also has a major impact on AHN (this will be discussed in detail later), and changes in neurogenesis induced by the environment correlates with performance in hippocampaldependent learning tasks. These studies establish only a correlation; therefore, it is possible that other factors such as structural plasticity, neurotrophin or hormone levels also contribute to genetically and environmentally induced changes in hippocampus-dependent learning and memory.

Newborn neurons represent only a small cell population within the adult hippocampus. It is therefore difficult to imagine how such a small number of cells can influence the function of the hippocampus. Interestingly, 3- to 5-weekold new neurons exhibit a reduced threshold for induction of long-term potentiation [33]. Accordingly, it has been hypothesized that the new neurons that are young when events occur have a specialized role in encoding, storage and in temporally relating one event to another [1], explaining a possible requirement of newborn neurons in the process of learning and memory.

To investigate whether hippocampal neurogenesis is required for hippocampus-dependent learning tasks, a variety of approaches have been taken to reduce or even ablate completely dividing cells in the hippocampus. Blockade of neurogenesis has been achieved with pharmacological, radiological and genetic strategies (reviewed in [22]). None of these methods specifically ablate adult progenitors and lead sometimes to controversial results.
These divergences might be due to differences in animal species, strains and the behavioural procedures. Moreover, all current studies have employed behavioural tasks based on lesion models where the whole hippocampus is affected. Impaired learning and memory caused by a decreased AHN would be easier to detect if the test were targeted at challenging the newborn neurons as they constitute only a small volume in the hippocampal structure. Therefore, to ultimately prove the function of AHN, approaches with selective ablation of newborn neurons in the dentate gyrus associated with specific behavioural tests need to be developed in the future.

\section{Mood regulation}

Recently, it has been proposed that AHN might play a role in mood regulation and in the aetiology of major depression [7, 120]. This idea arises from two lines of evidence. The first is that AHN is reduced by stressful experiences, a causal factor in the pathogenesis of major depression. Moreover, AHN is reduced in animal models of depression [19]. The second line of evidence indicates that many treatments for depression have been shown to enhance neurogenesis in laboratory animals; these factors include electroconvulsive therapy (ECT) [100] and common antidepressant drugs, such as selective serotonin reuptake inhibitors (SSRIs) [72]. The long time scale for recovery when humans are treated pharmacologically for depression (several weeks) parallels the long time scale of stimulated neurogenesis that is induced by ECT and SSRIs in nondepressed animals [72, 100]. Moreover, the effects of SSRIs on neurogenesis are selective for the hippocampus, leaving the ongoing stem cell proliferation in the SVZ unchanged [23]. Finally, in several animal models of depression, disruption of neurogenesis blocks the behavioural efficacy of SSRIs [98].

One of the mechanisms thought to mediate reduction of AHN by stress is the elevation of corticosterone by an activated hypothalamic-pituitary-adrenal axis. Indeed, corticosterone decreases cell proliferation, whereas adrenalectomy increases AHN. Moreover, glucocorticoid levels are increased in a variety of stress paradigms and adrenalectomy prevents the stress-induced suppression of AHN (reviewed in [79]).

One of the molecular candidates for mediating both neurogenic and behavioural effects of antidepressant is BDNF. Indeed, the levels of BDNF expression and AHN are co-regulated by both stress and antidepressants [21]. Moreover, infusion of BDNF into the dentate gyrus mimics the effect of antidepressants, but antidepressants fail to increase AHN with compromised BDNF-TrkB signalling, suggesting that this pathway is required for neurogenesis induced by antidepressants [65]. 
Adult hippocampal neurogenesis in CNS pathologies

AHN responds to neurodegenerative diseases such as Alzheimer's and Parkinson's diseases. Conflicting observations have been reported on the level of AHN in Alzheimer's disease mouse models, but the majority reports a decrease (reviewed in [58]). Mouse models of Parkinson's disease over-expressing the wild-type human $\alpha$-synuclein show a decrease in the survival rate of newborn hippocampal neurons (reviewed in [111]). AHN is also influenced by many other pathological conditions. For example, it is increased in epilepsy [44] and stroke [115], whereas it is decreased in HIV infection [87], and the integration of newborn neurons is disrupted by CNS inflammation [41]. It is apparent that AHN is influenced by neurological diseases; however, further studies are needed to understand the roles and consequences of AHN changes in pathological events.

\section{Environmental modulation of adult hippocampal neurogenesis}

AHN can be modulated by various physiological conditions and the environment (Fig. 2). Ageing has a negative effect on AHN, and aged rodents display impaired learning and memory abilities (reviewed in [55]). Stress is also a major negative regulator of $\mathrm{AHN}$, inducing depressive behaviour (reviewed in [79]). Sleep has recently appeared as another important regulator of AHN. Whilst disruption of sleep for a period shorter than 1 day has little effect on the basal rate of cell proliferation, prolonged restriction or disruption of sleep leads to a major decrease in hippocampal neurogenesis. It has been proposed that adverse effects of sleep disruption may be mediated by stress and glucocorticoids. However, a number of studies clearly show that prolonged sleep loss can inhibit hippocampal neurogenesis independently of adrenal stress hormones (reviewed in [77]). Interestingly, sleep deprivation also disturbs memory formation (reviewed in [105]) and this suggests that promoting AHN may be a mechanism by which sleep supports learning and memory processes. Social isolation is a stressful experience in rodents and has been shown to be another negative regulator of AHN that correlates with learning abilities [69]. Pregnancy [95] and maternal experiences [64] in rodent also have a negative impact on AHN. These are associated with a decline in performance in hippocampus-dependent tasks during pregnancy and the reduced AHN may be an outcome of pregnancy-induced changes in the immune response rather than of hormonal changes [95]. During the postpartum period, the decrease in AHN is dependent on elevated basal glucocorticoid levels [64]. Decreases in AHN during the postpartum period could be linked to postpartum depression experienced by some women.

In contrast, running and enriched environment promote AHN and enhanced spatial learning abilities. Running increases the proliferation [117], whereas enriched environment increases the survival rate of newborn neurons $[52,109]$. Both enriched environment and exercise lead to increased synaptic formation and up-regulation of neurotrophins (e.g. BDNF); however, they most likely act via dissociable pathways. Olson et al. [88] suggest that exercise leads to the convergence of key somatic and cerebral factors in the dentate gyrus to induce cell proliferation, whereas enriched environment induces cell survival by cortical restructuring as a means of promoting survival. The regulation of $\mathrm{AHN}$ by neural activity suggests that learning might also induce the activation of newborn neurons and enhance their survival and incorporation into circuits. Indeed, AHN is increased upon learning, but only by learning tasks that depend on the hippocampus (reviewed in [63]).

The deleterious effect of many negative regulators of AHN, including ageing [50], stress/depression (reviewed in [10]) and pregnancy [95], can be offset by running or providing an enriched environment in rodents. However, the molecular mechanisms by which physiological and environmental changes influence AHN remain to be fully understood.

\section{Dietary modulation of adult hippocampal neurogenesis}

Diet is another important environmental factor that can influence AHN. Diet can impact on AHN from four different levels: calorie intake, meal frequency, meal texture and meal content (Fig. 3). Not only do these four parameters modulate AHN in rodents (Table 1), but independent rodent studies and intervention or epidemiological studies in human have shown that they also modulate cognitive performance and mood (Table 2).

Calorie restriction can extend lifespan, improve behavioural outcomes in some experimental animal models of neurodegenerative disorders and enhance spatial learning (reviewed in [76]). It was shown more recently that a reduction in calorie intake of $30-40 \%$ increases AHN in rodents, and that this effect is partly mediated by BDNF [61, 62]. We have also found that independent of calorie intake, meal frequency is a key player in modulating AHN. Indeed, without reducing calorie intake, extending the time between meals increases AHN. It also changes hippocampal gene expression and correlates with performance in hippocampus-dependent tasks and mood (S. Thuret, unpublished data). However, further studies are ongoing to understand the mechanisms by which calorie restriction and meal 
Fig. 2 Overview of

physiological and

environmental modulation of

adult hippocampal neurogenesis and its impact on learning and memory abilities and mood. The dotted square contains the enlarged hippocampus. The red dots symbolize newborn neurons in the dentate gyrus $(D G)$

Fig. 3 Overview of the impact of diet on adult hippocampal neurogenesis. The red dots symbolize newborn neurons in the dentate gyrus of the hippocampus
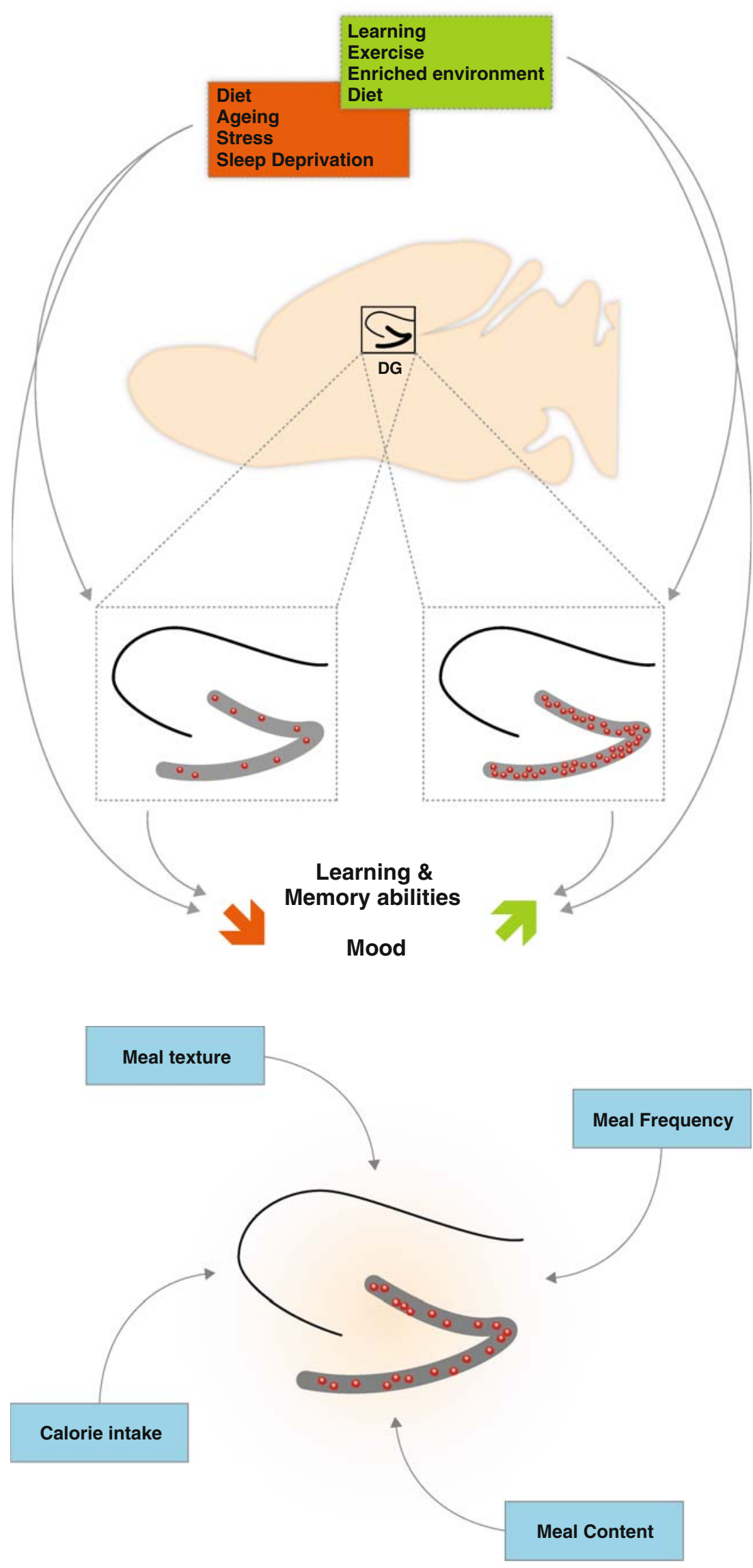
Table 1 Modulation of adult hippocampal neurogenesis (AHN) by diet

\begin{tabular}{|c|c|c|c|}
\hline Diet & Study models & Effect on AHN & References \\
\hline \multirow[t]{2}{*}{ Caloric restriction/dietary restriction } & Rat & Increased survival & {$[60]$} \\
\hline & Mouse & Increased survival & {$[62],[61],[54],[8]$} \\
\hline Omega 3 fatty acids & Rat & Increased (DHA) & [46] \\
\hline Flavonoids & Rat, chronically stressed & Increased proliferation & [3] \\
\hline Blueberry & Rat & Increased proliferation & {$[12]$} \\
\hline Curcumin low concentrations & Mouse & Increased proliferation & [53] \\
\hline Retinoic acid excess & Mouse & Decreased proliferation & {$[16]$} \\
\hline Vitamin A deficiency & Rat & Decreased proliferation (rescued with retinoic acid) & [9] \\
\hline Thiamine deficiency & Mouse & Decreased proliferation/survival & [128] \\
\hline Zinc deficiency & Rat male & Decreased proliferation/survival & [14] \\
\hline Folate deficiency & Mouse & Inhibited proliferation & {$[56]$} \\
\hline \multirow[t]{2}{*}{ Increased homocysteine } & Mouse & Inhibited proliferation & [93] \\
\hline & & & [57] \\
\hline \multirow[t]{2}{*}{ High fat } & Male rat & Decreased proliferation & [67] \\
\hline & Female rat & No change & \\
\hline Soft diet & Rat & Decreased proliferation & [4] \\
\hline \multicolumn{4}{|l|}{ Caffeine } \\
\hline At physiologically relevant doses & Mouse & Decreased proliferation & {$[121]$} \\
\hline At supraphysiological doses & Mouse & Increased proliferation/decreased survival & {$[121]$} \\
\hline Low doses, chronically & Rat & Decreased proliferation & {$[36]$} \\
\hline \multirow[t]{2}{*}{ Ethanol } & Rat & Decreased proliferation & [84], [37] \\
\hline & Mouse & Decreased proliferation & {$[103]$} \\
\hline
\end{tabular}

DHA docosahexaenoic acid

frequency modulate AHN and mental health. Interestingly, food texture also has an impact on AHN; rats fed with a soft diet, as opposed to a solid/hard diet, exhibit decreased hippocampal progenitor cell proliferation. The authors hypothesize that chewing resulting in cell proliferation is related to corticosterone levels [4]. Interestingly, independent studies have shown impairment in learning and memory abilities with similar soft diets [59, 114]. If chewing plays a role in AHN, these data could be particularly relevant to the ageing population with cognitive decline where dental weakening might limit the chewing ability.

Meal content offers the most flexibility to regulate AHN, as a variety of bioactives/nutrients have been identified as potential modulators. For example flavonoids, which are enriched in foods such as cocoa and blueberries, have been shown to increase AHN in chronically stressed rats [3], and the authors hypothesized that this effect might be mediated by BDNF. Moreover, independent studies have shown that treatment with flavonoids improves symptoms of depression [18] and improves spatial working memory in ageing rats [122]. Interestingly Williams et al. [122] have also identified BDNF as a potential mediator of the effect of flavonoids on cognition. Deficiency in zinc inhibits AHN [14] and induces depression in rodents [110], whereas independent intervention studies have shown the efficacy of zinc supplements in improving symptoms of depression (for review [108]). Corniola et al. [14] hypothesized that zinc plays a role in AHN by regulating p53-dependent molecular mechanisms that control neuronal precursor cell proliferation and survival.

Some bioactives act in a dose-dependent manner on AHN. Some can induce AHN at low doses or at a very precise physiological dosage and inhibit AHN at high doses. For example, excess retinoic acid decreases AHN and leads to depressive behaviour and impaired spatial learning in rodents $[16,86]$. A deficiency in retinoic acid will lead to similar effects on AHN and mental health, but its effects are reversed by re-establishing a normal level [9]. Caffeine is another dose-dependent bioactive. Indeed, consumed at low doses chronically, Han et al. [36] have shown that it decreases AHN and performance in hippocampus-dependent learning tasks in rodents. Interestingly, at supraphysiological doses, there is an increase in proliferation of neuronal precursors. However, neurons induced in response to supra-physiological levels of caffeine have a lower survival rate than control cells and increased proliferation does not yield an increase in AHN [121]. Curcumin is a natural phenolic component of yellow curry spice that increases AHN in rodents [53] and epidemiological studies have reported better cognitive performance from curry 
Table 2 Modulation of learning and memory and depressive behaviour by diet

\begin{tabular}{|c|c|c|c|c|}
\hline Diet & Effect on learning and memory & Effect on depressive behaviour & Study models & References \\
\hline \multirow{4}{*}{$\begin{array}{l}\text { Caloric/dietary } \\
\text { restriction }\end{array}$} & Enhanced spatial learning in aged rats & & Rat & [104] \\
\hline & $\begin{array}{l}\text { Enhanced cognitive performance in } \\
\text { females only }\end{array}$ & & Rat & [74] \\
\hline & $\begin{array}{l}\text { Increased learning and motor } \\
\text { performance }\end{array}$ & & Mouse & {$[40]$} \\
\hline & Increased learning consolidation & & Mouse & {$[28]$} \\
\hline \multirow[t]{8}{*}{ Omega 3 fatty acids } & & Improved (EPA) & Human & {$[42]$} \\
\hline & & Delayed onset of depressive periods & Human (bipolar) & {$[106]$} \\
\hline & & Decreased & Human (bipolar) & [89] \\
\hline & & No benefit $6 \mathrm{~g} /$ day EPA & Human (bipolar) & {$[47]$} \\
\hline & & Improvement with $1 \mathrm{~g} /$ day EPA & Human (bipolar) & {$[30]$} \\
\hline & & $\begin{array}{l}\text { Various effects with various } \\
\text { concentrations of various fatty } \\
\text { acids }\end{array}$ & Human & For review: [5] \\
\hline & Improved spatial memory & & $\begin{array}{l}\text { Mouse } \\
\text { Alzheimer } \\
\text { model }\end{array}$ & {$[38]$} \\
\hline & $\begin{array}{l}\text { Improved acquisition and retention in a } \\
\text { T-maze foot shock avoidance test }\end{array}$ & & $\begin{array}{l}\text { Mouse } \\
\text { Senescence- } \\
\text { Accelerated }\end{array}$ & {$[92]$} \\
\hline \multirow[t]{2}{*}{ Flavonoids } & & Improved & Rat & [18] \\
\hline & Improved & & & For review: [119] \\
\hline Blueberry & Increased spatial memory & & Rat & {$[122]$} \\
\hline \multirow{2}{*}{$\begin{array}{l}\text { Polyphenol/flavonoids/ } \\
\text { berry }\end{array}$} & Positive impact & & Various animals & For review: [123] \\
\hline & & Improved & Rat & [78] \\
\hline Curcumin & Improved cognitive performance & & Human & {$[83]$} \\
\hline Retinoic acid excess & & Increased & Mouse adult & {$[86]$} \\
\hline \multirow{2}{*}{$\begin{array}{l}\text { Vitamin A/retinoid } \\
\text { deficiency }\end{array}$} & Impaired spatial learning and memory & & Rat adult & {$[13]$} \\
\hline & Impaired relational memory & & Mouse adult & {$[25]$} \\
\hline \multirow[t]{3}{*}{ Zinc } & & Improved & Rodents & For review: [108] \\
\hline & & Improved & Human & For review: [108] \\
\hline & & Improved & Human & {$[85]$} \\
\hline \multirow[t]{2}{*}{ High fat } & Decreased spatial learning & & Rat & {$[80]$} \\
\hline & $\begin{array}{l}\text { Decreased learning and memory and } \\
\text { Increased risk for dementia }\end{array}$ & & Rat & {$[124]$} \\
\hline High sugar & Impaired spatial learning & & Rat & {$[107]$} \\
\hline $\begin{array}{l}\text { Low glucose } \\
\text { (extracellular) }\end{array}$ & Impaired memory & & Rat aged & {$[34]$} \\
\hline Soft diet & $\begin{array}{l}\text { Impairment of learning ability and } \\
\text { memory }\end{array}$ & & $\begin{array}{l}\text { Rat Alzheimer } \\
\text { model }\end{array}$ & [59] \\
\hline \multirow[t]{2}{*}{ Caffeine } & Improved object recognition & & Mouse & [15] \\
\hline & & Reduced risk & Human & {$[101]$} \\
\hline \multirow[t]{2}{*}{ Ethanol } & $\begin{array}{l}\text { Improved associative learning with } \\
\text { moderate chronic consumption }\end{array}$ & & Mouse male & [94] \\
\hline & Deficits & & Human & [91] \\
\hline
\end{tabular}

EPA eicosapentaenoic acid

consumption in ageing populations [83]. Moreover, in vitro studies have shown that curcumin exerted biphasic effects on progenitor cells; low concentrations stimulated cell proliferation, whereas high concentrations were cytotoxic.
Curcumin activates extracellular signal-regulated kinases (ERKs) and p38 kinases, cellular signal transduction pathways known to be involved in the regulation of neuronal plasticity and stress responses [53]. 
Finally, it is important to note that independent of calorie intake, diets with high-fat content are detrimental and impair AHN in male rats. The authors hypothesize that high dietary fat intake disrupts AHN through an increase in serum corticosterone levels, and that males are more susceptible than females [67].

BDNF and corticosterone levels appear to be common protagonists of dietary modulated AHN; however, they are unlikely to be the only mediators. For example, further studies will need to be done to investigate if dietary factors modulate AHN by modifying the neurogenic niche. The vasculature [90] and astrocytes [102] are important constituents of the neurogenic niche and interestingly flavanol-rich foods can positively enhance cortical blood flow [27, 29] and are regulators of astrocytic signalling pathways and gene expression [6]. Such changes in the neurogenic niche in response to flavanols might underpin neuro-cognitive improvements through the concurrent promotion of adult hippocampal neurogenesis. Forthcoming studies will not only need to refine the molecular mechanisms by which food intake influences AHN, but also consider the role of epigenetic mechanisms. Indeed, there is increasing evidence that epigenetic mechanisms underlie both AHN [44] and changes in gene expression in response to diet [75]. Future research will need to investigate if diet can modulate AHN through epigenetic changes.

\section{Conclusion and perspectives}

It is now getting clearer that AHN affects cognition and mood. It is also firmly established that nutrition has an impact on cognition and mood. Therefore, AHN is emerging as a possible mediator of the effect of certain food on cognition and mood. Consequently, modulating AHN by diet could be a target of choice to prevent cognitive decline during ageing, as well as to counteract the effect of stress and prevent depression. However, further studies are needed to confirm that AHN does mediate the effect of certain diet on mental health, and additional investigations are essential to understand the mechanisms by which diet modulates AHN.

Acknowledgments The authors thank Clemens Hackl for his contribution to the illustrations and Graham Cocks for the helpful comments. This work was supported by the Medical Research Council and the Research Council UK.

\section{References}

1. Aimone JB, Wiles J, Gage FH (2009) Computational influence of adult neurogenesis on memory encoding. Neuron 61:187-202
2. Alvarez-Buylla A, Seri B, Doetsch F (2002) Identification of neural stem cells in the adult vertebrate brain. Brain Res Bull 57:751-758

3. An L, Zhang YZ, Yu NJ, Liu XM, Zhao N, Yuan L, Chen HX, Li YF (2008) The total flavonoids extracted from XiaobuxinTang up-regulate the decreased hippocampal neurogenesis and neurotrophic molecules expression in chronically stressed rats. Prog Neuropsychopharmacol Biol Psychiatry 32:1484-1490

4. Aoki H, Kimoto K, Hori N, Toyoda M (2005) Cell proliferation in the dentate gyrus of rat hippocampus is inhibited by soft diet feeding. Gerontology 51:369-374

5. Appleton KM, Hayward RC, Gunnell D, Peters TJ, Rogers PJ, Kessler D, Ness AR (2006) Effects of n-3 long-chain polyunsaturated fatty acids on depressed mood: systematic review of published trials. Am J Clin Nutr 84:1308-1316

6. Bahia PK, Rattray M, Williams RJ (2008) Dietary flavonoid (-) epicatechin stimulates phosphatidylinositol 3-kinase-dependent anti-oxidant response element activity and up-regulates glutathione in cortical astrocytes. J Neurochem 106:2194-2204

7. Becker S, Wojtowicz JM (2007) A model of hippocampal neurogenesis in memory and mood disorders. Trends Cogn Sci 11:70-76

8. Bondolfi L, Ermini F, Long JM, Ingram DK, Jucker M (2004) Impact of age and caloric restriction on neurogenesis in the dentate gyrus of C57BL/6 mice. Neurobiol Aging 25:333340

9. Bonnet E, Touyarot K, Alfos S, Pallet V, Higueret P, Abrous DN (2008) Retinoic acid restores adult hippocampal neurogenesis and reverses spatial memory deficit in vitamin A-deprived rats. PLoS ONE 3:e3487

10. Brene S, Bjornebekk A, Aberg E, Mathe AA, Olson L, Werme M (2007) Running is rewarding and antidepressive. Physiol Behav 92:136-140

11. Cameron HA, Gould E (1994) Adult neurogenesis is regulated by adrenal steroids in the dentate gyrus. Neuroscience 61:203209

12. Casadesus G, Shukitt-Hale B, Stellwagen HM, Zhu X, Lee HG, Smith MA, Joseph JA (2004) Modulation of hippocampal plasticity and cognitive behavior by short-term blueberry supplementation in aged rats. Nutr Neurosci 7:309-316

13. Cocco S, Diaz G, Stancampiano R, Diana A, Carta M, Curreli R, Sarais L, Fadda F (2002) Vitamin A deficiency produces spatial learning and memory impairment in rats. Neuroscience 115:475-482

14. Corniola RS, Tassabehji NM, Hare J, Sharma G, Levenson CW (2008) Zinc deficiency impairs neuronal precursor cell proliferation and induces apoptosis via p53-mediated mechanisms. Brain Res 1237:52-61

15. Costa MS, Botton PH, Mioranzza S, Ardais AP, Moreira JD, Souza DO, Porcincula LO (2008) Caffeine improves adult mice performance in the object recognition task and increases BDNF and TrkB independent on phospho-CREB immunocontent in the hippocampus. Neurochem Int 53:89-94

16. Crandall J, Sakai Y, Zhang J, Koul O, Mineur Y, Crusio WE, McCaffery P (2004) 13-cis-retinoic acid suppresses hippocampal cell division and hippocampal-dependent learning in mice. Proc Natl Acad Sci USA 101:5111-5116

17. Denli AM, Cao X, Gage FH (2009) miR-9 and TLX: chasing tails in neural stem cells. Nat Struct Mol Biol 16:346-347

18. Dimpfel W (2009) Rat electropharmacograms of the flavonoids rutin and quercetin in comparison to those of moclobemide and clinically used reference drugs suggest antidepressive and/or neuroprotective action. Phytomedicine 16:287-294

19. Dranovsky A, Hen R (2006) Hippocampal neurogenesis: regulation by stress and antidepressants. Biol Psychiatry 59:11361143 
20. Duan X, Chang JH, Ge S, Faulkner RL, Kim JY, Kitabatake Y, Liu XB, Yang CH, Jordan JD, Ma DK, Liu CY, Ganesan S, Cheng HJ, Ming GL, Lu B, Song H (2007) Disrupted-in-Schizophrenia 1 regulates integration of newly generated neurons in the adult brain. Cell 130:1146-1158

21. Duman RS, Monteggia LM (2006) A neurotrophic model for stress-related mood disorders. Biol Psychiatry 59:1116-1127

22. Ehninger D, Kempermann G (2008) Neurogenesis in the adult hippocampus. Cell Tissue Res 331:243-250

23. Encinas JM, Vaahtokari A, Enikolopov G (2006) Fluoxetine targets early progenitor cells in the adult brain. Proc Natl Acad Sci USA 103:8233-8238

24. Eriksson PS, Perfilieva E, Bjork-Eriksson T, Alborn AM, Nordborg C, Peterson DA, Gage FH (1998) Neurogenesis in the adult human hippocampus. Nat Med 4:1313-1317

25. Etchamendy N, Enderlin V, Marighetto A, Pallet V, Higueret $P$, Jaffard R (2003) Vitamin A deficiency and relational memory deficit in adult mice: relationships with changes in brain retinoid signalling. Behav Brain Res 145:37-49

26. Fedorova I, Salem N Jr (2006) Omega-3 fatty acids and rodent behavior. Prostaglandins Leukot Essent Fatty Acids 75:271-289

27. Fisher ND, Sorond FA, Hollenberg NK (2006) Cocoa flavanols and brain perfusion. J Cardiovasc Pharmacol 47(Suppl 2):S210-S214

28. Fontan-Lozano A, Saez-Cassanelli JL, Inda MC, de los SantosArteaga M, Sierra-Dominguez SA, Lopez-Lluch G, DelgadoGarcia JM, Carrion AM (2007) Caloric restriction increases learning consolidation and facilitates synaptic plasticity through mechanisms dependent on NR2B subunits of the NMDA receptor. J Neurosci 27:10185-10195

29. Francis ST, Head K, Morris PG, Macdonald IA (2006) The effect of flavanol-rich cocoa on the fMRI response to a cognitive task in healthy young people. J Cardiovasc Pharmacol 47(Suppl 2):S215-S220

30. Frangou S, Lewis M, McCrone P (2006) Efficacy of ethyleicosapentaenoic acid in bipolar depression: randomised doubleblind placebo-controlled study. Br J Psychiatry 188:46-50

31. Freemantle E, Vandal M, Tremblay-Mercier J, Tremblay S, Blachere JC, Begin ME, Brenna JT, Windust A, Cunnane SC (2006) Omega-3 fatty acids, energy substrates, and brain function during aging. Prostaglandins Leukot Essent Fatty Acids $75: 213-220$

32. Gage FH (2000) Mammalian neural stem cells. Science 287:1433-1438

33. Ge S, Yang CH, Hsu KS, Ming GL, Song H (2007) A critical period for enhanced synaptic plasticity in newly generated neurons of the adult brain. Neuron 54:559-566

34. Gold PE (2005) Glucose and age-related changes in memory. Neurobiol Aging 26:60-64

35. Gomez-Pinilla F (2008) Brain foods: the effects of nutrients on brain function. Nat Rev Neurosci 9:568-578

36. Han ME, Park KH, Baek SY, Kim BS, Kim JB, Kim HJ, Oh SO (2007) Inhibitory effects of caffeine on hippocampal neurogenesis and function. Biochem Biophys Res Commun 356:976-980

37. He J, Nixon K, Shetty AK, Crews FT (2005) Chronic alcohol exposure reduces hippocampal neurogenesis and dendritic growth of newborn neurons. Eur J Neurosci 21:2711-2720

38. Hooijmans CR, Van der Zee CEEM, Dederen PJ, Brouwer KM, Reijmer YD, van Groen T, Broersen LM, Ls tjohann D, Heerschap A, Kiliaan AJ (2009) DHA and cholesterol containing diets influence Alzheimer-like pathology, cognition and cerebral vasculature in APPswe/PS1dE9 mice. Neurobiol Dis 33:482-498

39. Hsieh J, Nakashima K, Kuwabara T, Mejia E, Gage FH (2004) Histone deacetylase inhibition-mediated neuronal differentiation of multipotent adult neural progenitor cells. Proc Natl Acad Sci USA 101:16659-16664
40. Ingram DK, Weindruch R, Spangler EL, Freeman JR, Walford RL (1987) Dietary restriction benefits learning and motor performance of aged mice. J Gerontol 42:78-81

41. Jakubs K, Bonde S, Iosif RE, Ekdahl CT, Kokaia Z, Kokaia M, Lindvall O (2008) Inflammation regulates functional integration of neurons born in adult brain. J Neurosci 28:12477-12488

42. Jazayeri S, Tehrani-Doost M, Keshavarz SA, Hosseini M, Djazayery A, Amini H, Jalali M, Peet M (2008) Comparison of therapeutic effects of omega-3 fatty acid eicosapentaenoic acid and fluoxetine, separately and in combination, in major depressive disorder. Aust N Z J Psychiatry 42:192-198

43. Jessberger S, Aigner S, Clemenson GD Jr, Toni N, Lie DC, Karalay O, Overall R, Kempermann G, Gage FH (2008) Cdk5 regulates accurate maturation of newborn granule cells in the adult hippocampus. PLoS Biol 6:e272

44. Jessberger S, Nakashima K, Clemenson GD Jr, Mejia E, Mathews E, Ure K, Ogawa S, Sinton CM, Gage FH, Hsieh J (2007) Epigenetic modulation of seizure-induced neurogenesis and cognitive decline. J Neurosci 27:5967-5975

45. Jiao JW, Feldheim DA, Chen DF (2008) Ephrins as negative regulators of adult neurogenesis in diverse regions of the central nervous system. Proc Natl Acad Sci USA 105:8778-8783

46. Kawakita E, Hashimoto M, Shido O (2006) Docosahexaenoic acid promotes neurogenesis in vitro and in vivo. Neuroscience 139:991-997

47. Keck PE Jr, Mintz J, McElroy SL, Freeman MP, Suppes T, Frye MA, Altshuler LL, Kupka R, Nolen WA, Leverich GS, Denicoff KD, Grunze H, Duan N, Post RM (2006) Double-blind, randomized, placebo-controlled trials of ethyl-eicosapentanoate in the treatment of bipolar depression and rapid cycling bipolar disorder. Biol Psychiatry 60:1020-1022

48. Kempermann G, Gage FH (2000) Neurogenesis in the adult hippocampus. Novartis Found Symp 231:220-235 discussion 235-41, 302-6

49. Kempermann G, Gage FH (2002) Genetic influence on phenotypic differentiation in adult hippocampal neurogenesis. Brain Res Dev Brain Res 134:1-12

50. Kempermann G, Gast D, Gage FH (2002) Neuroplasticity in old age: sustained fivefold induction of hippocampal neurogenesis by long-term environmental enrichment. Ann Neurol 52:135-143

51. Kempermann G, Gast D, Kronenberg G, Yamaguchi M, Gage FH (2003) Early determination and long-term persistence of adult-generated new neurons in the hippocampus of mice. Development 130:391-399

52. Kempermann G, Kuhn HG, Gage FH (1997) More hippocampal neurons in adult mice living in an enriched environment. Nature 386:493-495

53. Kim SJ, Son TG, Park HR, Park M, Kim MS, Kim HS, Chung HY, Mattson MP, Lee J (2008) Curcumin stimulates proliferation of embryonic neural progenitor cells and neurogenesis in the adult hippocampus. J Biol Chem 283:14497-14505

54. Kitamura T, Mishina M, Sugiyama H (2006) Dietary restriction increases hippocampal neurogenesis by molecular mechanisms independent of NMDA receptors. Neurosci Lett 393:94-96

55. Klempin F, Kempermann G (2007) Adult hippocampal neurogenesis and aging. Eur Arch Psychiatry Clin Neurosci 257:271-280

56. Kronenberg G, Harms C, Sobol RW, Cardozo-Pelaez F, Linhart H, Winter B, Balkaya M, Gertz K, Gay SB, Cox D, Eckart S, Ahmadi M, Juckel G, Kempermann G, Hellweg R, Sohr R, Hortnagl H, Wilson SH, Jaenisch R, Endres M (2008) Folate deficiency induces neurodegeneration and brain dysfunction in mice lacking uracil DNA glycosylase. J Neurosci 28:7219-7230

57. Kruman II, Mouton PR, Emokpae R Jr, Cutler RG, Mattson MP (2005) Folate deficiency inhibits proliferation of adult hippocampal progenitors. Neuroreport 16:1055-1059 
58. Kuhn HG, Cooper-Kuhn CM, Boekhoorn K, Lucassen PJ (2007) Changes in neurogenesis in dementia and Alzheimer mouse models: are they functionally relevant? Eur Arch Psychiatry Clin Neurosci 257:281-289

59. Kushida S, Kimoto K, Hori N, Toyoda M, Karasawa N, Yamamoto T, Kojo A, Onozuka M (2008) Soft-diet feeding decreases dopamine release and impairs aversion learning in Alzheimer model rats. Neurosci Lett 439:208-211

60. Lee J, Duan W, Long JM, Ingram DK, Mattson MP (2000) Dietary restriction increases the number of newly generated neural cells, and induces BDNF expression, in the dentate gyrus of rats. J Mol Neurosci 15:99-108

61. Lee J, Duan W, Mattson MP (2002) Evidence that brain-derived neurotrophic factor is required for basal neurogenesis and mediates, in part, the enhancement of neurogenesis by dietary restriction in the hippocampus of adult mice. J Neurochem 82:13671375

62. Lee J, Seroogy KB, Mattson MP (2002) Dietary restriction enhances neurotrophin expression and neurogenesis in the hippocampus of adult mice. J Neurochem 80:539-547

63. Leuner B, Gould E, Shors TJ (2006) Is there a link between adult neurogenesis and learning? Hippocampus 16:216-224

64. Leuner B, Mirescu C, Noiman L, Gould E (2007) Maternal experience inhibits the production of immature neurons in the hippocampus during the postpartum period through elevations in adrenal steroids. Hippocampus 17:434-442

65. Li Y, Luikart BW, Birnbaum S, Chen J, Kwon CH, Kernie SG, Bassel-Duby R, Parada LF (2008) TrkB regulates hippocampal neurogenesis and governs sensitivity to antidepressive treatment. Neuron 59:399-412

66. Lie DC, Colamarino SA, Song HJ, Desire L, Mira H, Consiglio A, Lein ES, Jessberger S, Lansford H, Dearie AR, Gage FH (2005) Wnt signalling regulates adult hippocampal neurogenesis. Nature 437:1370-1375

67. Lindqvist A, Mohapel P, Bouter B, Frielingsdorf H, Pizzo D, Brundin P, Erlanson-Albertsson C (2006) High-fat diet impairs hippocampal neurogenesis in male rats. Eur J Neurol 13:13851388

68. Logan AC (2004) Omega-3 fatty acids and major depression: a primer for the mental health professional. Lipids Health Dis 3:25

69. Lu L, Bao G, Chen H, Xia P, Fan X, Zhang J, Pei G, Ma L (2003) Modification of hippocampal neurogenesis and neuroplasticity by social environments. Exp Neurol 183:600-609

70. Ma DK, Jang MH, Guo JU, Kitabatake Y, Chang ML, PowAnpongkul N, Flavell RA, Lu B, Ming GL, Song H (2009) Neuronal activity-induced Gadd45b promotes epigenetic DNA demethylation and adult neurogenesis. Science 323:1074-1077

71. Mak GK, Enwere EK, Gregg C, Pakarainen T, Poutanen M, Huhtaniemi I, Weiss S (2007) Male pheromone-stimulated neurogenesis in the adult female brain: possible role in mating behavior. Nat Neurosci 10:1003-1011

72. Malberg JE, Eisch AJ, Nestler EJ, Duman RS (2000) Chronic antidepressant treatment increases neurogenesis in adult rat hippocampus. J Neurosci 20:9104-9110

73. Mao Y, Ge X, Frank CL, Madison JM, Koehler AN, Doud MK, Tassa C, Berry EM, Soda T, Singh KK, Biechele T, Petryshen TL, Moon RT, Haggarty SJ, Tsai LH (2009) Disrupted in schizophrenia 1 regulates neuronal progenitor proliferation via modulation of GSK3beta/beta-catenin signaling. Cell 136:1017-1031

74. Martin B, Pearson M, Kebejian L, Golden E, Keselman A, Bender M, Carlson O, Egan J, Ladenheim B, Cadet JL, Becker KG, Wood W, Duffy K, Vinayakumar P, Maudsley S, Mattson MP (2007) Sex-dependent metabolic, neuroendocrine, and cognitive responses to dietary energy restriction and excess. Endocrinology 148:4318-4333
75. Mathers JC (2006) Nutritional modulation of ageing: genomic and epigenetic approaches. Mech Ageing Dev 127:584-589

76. Mattson MP (2000) Neuroprotective signaling and the aging brain: take away my food and let me run. Brain Res 886:47-53

77. Meerlo P, Mistlberger RE, Jacobs BL, Craig Heller H, McGinty D (2009) New neurons in the adult brain: The role of sleep and consequences of sleep loss. Sleep Med Rev 13(3):187-194

78. Messaoudi M, Bisson JF, Nejdi A, Rozan P, Javelot H (2008) Antidepressant-like effects of a cocoa polyphenolic extract in Wistar-Unilever rats. Nutr Neurosci 11:269-276

79. Mirescu C, Gould E (2006) Stress and adult neurogenesis. Hippocampus 16:233-238

80. Molteni R, Barnard RJ, Ying Z, Roberts CK, Gomez-Pinilla F (2002) A high-fat, refined sugar diet reduces hippocampal brainderived neurotrophic factor, neuronal plasticity, and learning. Neuroscience 112:803-814

81. Morrison SJ, Spradling AC (2008) Stem cells and niches: mechanisms that promote stem cell maintenance throughout life. Cell 132:598-611

82. Mudo G, Bonomo A, Di Liberto V, Frinchi M, Fuxe K, Belluardo N (2009) The FGF-2/FGFRs neurotrophic system promotes neurogenesis in the adult brain. J Neural Transm 116(8):995-1005

83. Ng TP, Chiam PC, Lee T, Chua HC, Lim L, Kua EH (2006) Curry consumption and cognitive function in the elderly. Am J Epidemiol 164:898-906

84. Nixon K, Crews FT (2002) Binge ethanol exposure decreases neurogenesis in adult rat hippocampus. J Neurochem 83:1087-1093

85. Nowak G, Siwek M, Dudek D, Zieba A, Pilc A (2003) Effect of zinc supplementation on antidepressant therapy in unipolar depression: a preliminary placebo-controlled study. Pol J Pharmacol 55:1143-1147

86. O'Reilly KC, Shumake J, Bailey SJ, Gonzalez-Lima F, Lane MA (2009) Chronic 13-cis-retinoic acid administration disrupts network interactions between the raphe nuclei and the hippocampal system in young adult mice. Eur J Pharmacol 605:68-77

87. Okamoto S, Kang YJ, Brechtel CW, Siviglia E, Russo R, Clemente A, Harrop A, McKercher S, Kaul M, Lipton SA (2007) HIV/gp120 decreases adult neural progenitor cell proliferation via checkpoint kinase-mediated cell-cycle withdrawal and G1 arrest. Cell Stem Cell 1:230-236

88. Olson AK, Eadie BD, Ernst C, Christie BR (2006) Environmental enrichment and voluntary exercise massively increase neurogenesis in the adult hippocampus via dissociable pathways. Hippocampus 16:250-260

89. Osher Y, Bersudsky Y, Belmaker RH (2005) Omega-3 eicosapentaenoic acid in bipolar depression: report of a small openlabel study. J Clin Psychiatry 66:726-729

90. Palmer TD, Willhoite AR, Gage FH (2000) Vascular niche for adult hippocampal neurogenesis. J Comp Neurol 425:479-494

91. Parsons OA (1998) Neurocognitive deficits in alcoholics and social drinkers: a continuum? Alcohol Clin Exp Res 22:954-961

92. Petursdottir AL, Farr SA, Morley JE, Banks WA, Skuladottir GV (2008) Effect of dietary n-3 polyunsaturated fatty acids on brain lipid fatty acid composition, learning ability, and memory of senescence-accelerated mouse. J Gerontol Ser A Biol Sci Med Sci 63:1153-1160

93. Rabaneda LG, Carrasco M, Lopez-Toledano MA, MurilloCarretero M, Ruiz FA, Estrada C, Castro C (2008) Homocysteine inhibits proliferation of neuronal precursors in the mouse adult brain by impairing the basic fibroblast growth factor signaling cascade and reducing extracellular regulated kinase 1/2-dependent cyclin E expression. FASEB J 22:3823-3835

94. Robles N, Sabria J (2008) Effects of moderate chronic ethanol consumption on hippocampal nicotinic receptors and associative learning. Neurobiol Learn Mem 89:497-503 
95. Rolls A, Schori H, London A, Schwartz M (2008) Decrease in hippocampal neurogenesis during pregnancy: a link to immunity. Mol Psychiatry 13:468-469

96. Roybon L, Hjalt T, Stott S, Guillemot F, Li JY, Brundin P (2009) Neurogenin2 directs granule neuroblast production and amplification while NeuroD1 specifies neuronal fate during hippocampal neurogenesis. PLoS ONE 4:e4779

97. Sairanen M, Lucas G, Ernfors P, Castren M, Castren E (2005) Brain-derived neurotrophic factor and antidepressant drugs have different but coordinated effects on neuronal turnover, proliferation, and survival in the adult dentate gyrus. J Neurosci 25:1089-1094

98. Santarelli L, Saxe M, Gross C, Surget A, Battaglia F, Dulawa S, Weisstaub N, Lee J, Duman R, Arancio O, Belzung C, Hen R (2003) Requirement of hippocampal neurogenesis for the behavioral effects of antidepressants. Science 301:805-809

99. Scharfman H, Goodman J, Macleod A, Phani S, Antonelli C, Croll S (2005) Increased neurogenesis and the ectopic granule cells after intrahippocampal BDNF infusion in adult rats. Exp Neurol 192:348-356

100. Scott BW, Wojtowicz JM, Burnham WM (2000) Neurogenesis in the dentate gyrus of the rat following electroconvulsive shock seizures. Exp Neurol 165:231-236

101. Smith AP (2009) Caffeine, cognitive failures and health in a nonworking community sample. Hum Psychopharmacol 24:29-34

102. Song H, Stevens CF, Gage FH (2002) Astroglia induce neurogenesis from adult neural stem cells. Nature 417:39-44

103. Stevenson JR, Schroeder JP, Nixon K, Besheer J, Crews FT, Hodge CW (2008) Abstinence following alcohol drinking produces depression-like behavior and reduced hippocampal neurogenesis in mice. Neuropsychopharmacology 34:1209-1222

104. Stewart J, Mitchell J, Kalant N (1989) The effects of life-long food restriction on spatial memory in young and aged Fischer 344 rats measured in the eight-arm radial and the Morris water mazes. Neurobiol Aging 10:669-675

105. Stickgold R (2005) Sleep-dependent memory consolidation. Nature 437:1272-1278

106. Stoll AL, Severus WE, Freeman MP, Rueter S, Zboyan HA, Diamond E, Cress KK, Marangell LB (1999) Omega 3 fatty acids in bipolar disorder: a preliminary double-blind, placebocontrolled trial. Arch Gen Psychiatry 56:407-412

107. Stranahan AM, Norman ED, Lee K, Cutler RG, Telljohann RS, Egan JM, Mattson MP (2008) Diet-induced insulin resistance impairs hippocampal synaptic plasticity and cognition in middle-aged rats. Hippocampus 18:1085-1088

108. Szewczyk B, Poleszak E, Sowa-Kucma M, Siwek M, Dudek D, Ryszewska-Pokrasniewicz B, Radziwon-Zaleska M, Opoka W, Czekaj J, Pilc A, Nowak G (2008) Antidepressant activity of zinc and magnesium in view of the current hypotheses of antidepressant action. Pharmacol Rep 60:588-589

109. Tashiro A, Makino H, Gage FH (2007) Experience-specific functional modification of the dentate gyrus through adult neurogenesis: a critical period during an immature stage. J Neurosci 27:3252-3259

110. Tassabehji NM, Corniola RS, Alshingiti A, Levenson CW (2008) Zinc deficiency induces depression-like symptoms in adult rats. Physiol Behav 95:365-369

111. Thompson A, Boekhoorn K, Van Dam AM, Lucassen PJ (2008) Changes in adult neurogenesis in neurodegenerative diseases: cause or consequence? Genes Brain Behav 7(Suppl 1):28-42
112. Thuret S, Toni N, Aigner S, Yeo GW, Gage FH (2009) Hippocampus-dependent learning is associated with adult neurogenesis in MRL/MpJ mice. Hippocampus 19(7):658-669

113. Toni N, Laplagne DA, Zhao C, Lombardi G, Ribak CE, Gage FH, Schinder AF (2008) Neurons born in the adult dentate gyrus form functional synapses with target cells. Nat Neurosci 11:901-907

114. Tsutsui K, Kaku M, Motokawa M, Tohma Y, Kawata T, Fujita T, Kohno S, Ohtani J, Tenjoh K, Nakano M, Kamada H, Tanne $\mathrm{K}$ (2007) Influences of reduced masticatory sensory input from soft-diet feeding upon spatial memory/learning ability in mice. Biomed Res 28:1-7

115. Urbach A, Redecker C, Witte OW (2008) Induction of neurogenesis in the adult dentate gyrus by cortical spreading depression. Stroke 39:3064-3072

116. van Gelder BM, Tijhuis M, Kalmijn S, Kromhout D (2007) Fish consumption, n-3 fatty acids, and subsequent 5-y cognitive decline in elderly men: the Zutphen Elderly Study. Am J Clin Nutr 85:1142-1147

117. van Praag H, Kempermann G, Gage FH (1999) Running increases cell proliferation and neurogenesis in the adult mouse dentate gyrus. Nat Neurosci 2:266-270

118. van Praag H, Schinder AF, Christie BR, Toni N, Palmer TD, Gage FH (2002) Functional neurogenesis in the adult hippocampus. Nature 415:1030-1034

119. Vauzour D, Vafeiadou K, Rodriguez-Mateos A, Rendeiro C, Spencer JP (2008) The neuroprotective potential of flavonoids: a multiplicity of effects. Genes Nutr 3:115-126

120. Vollmayr B, Mahlstedt MM, Henn FA (2007) Neurogenesis and depression: what animal models tell us about the link. Eur Arch Psychiatry Clin Neurosci 257:300-303

121. Wentz CT, Magavi SSP (2009) Caffeine alters proliferation of neuronal precursors in the adult hippocampus. Neuropharmacology 56(6-7):994-1000

122. Williams CM, El Mohsen MA, Vauzour D, Rendeiro C, Butler LT, Ellis JA, Whiteman M, Spencer JP (2008) Blueberryinduced changes in spatial working memory correlate with changes in hippocampal CREB phosphorylation and brainderived neurotrophic factor (BDNF) levels. Free Radic Biol Med 45:295-305

123. Willis LM, Shukitt-Hale B, Joseph JA (2009) Recent advances in berry supplementation and age-related cognitive decline. Curr Opin Clin Nutr Metab Care 12:91-94

124. Winocur G, Greenwood CE (2005) Studies of the effects of high-fat diets on cognitive function in a rat model. Neurobiol Aging 26(Suppl 1):46-49

125. Zhang CL, Zou Y, He W, Gage FH, Evans RM (2008) A role for adult TLX-positive neural stem cells in learning and behaviour. Nature 451:1004-1007

126. Zhao C, Deng W, Gage FH (2008) Mechanisms and functional implications of adult neurogenesis. Cell 132:645-660

127. Zhao M, Li D, Shimazu K, Zhou YX, Lu B, Deng CX (2007) Fibroblast growth factor receptor-1 is required for long-term potentiation, memory consolidation, and neurogenesis. Biol Psychiatry 62:381-390

128. Zhao N, Zhong C, Wang Y, Zhao Y, Gong N, Zhou G, Xu T, Hong $Z$ (2008) Impaired hippocampal neurogenesis is involved in cognitive dysfunction induced by thiamine deficiency at early pre-pathological lesion stage. Neurobiol Dis 29:176-185 